\title{
NUMERICAL MODELLING OF THE MINING INDUCED HORIZONTAL DISPLACEMENT
}

\author{
KRZYSZTOF TAJDUŚ
}

Strata Mechanics Research Institute, Polish Academy of Sciences

\begin{abstract}
The paper presents results of numerical calculations and modeling of mining-induced surface deformation based on Finite Element Method (FEM). Applying the numerical method discussed to calculations allows us to assume a larger number of factors, such as rock mass structure, fracture network, rock properties, etc., which essentially affect the results obtained. On the basis of an elastic transversely isotropic model, an analysis of horizontal displacement distribution and surface subsidence was carried out for two sample regions of mines. The results of numerical calculations were later compared with the measured values. Such an analysis proved that the applied numerical model properly described distribution and values of subsidence and slope of subsidence trough, though there were serious differences in the values of calculated horizontal displacement, especially in areas of far influence range. In order to improve the matching, the influence of boundary conditions of the model on the value of calculated horizontal displacement was analyzed. The results are presented in graphs.
\end{abstract}

Key words: Finite Element Method, horizontal displacements, mining excavation

\section{INTRODUCTION}

Underground mining leads to deformations of surrounding rock mass, which appears in the surface in the form of subsidence trough. Such a phenomenon imposes serious problems, including negative economic consequences, by causing damage to surface buildings. Damage prevention is largely based on prediction. Nowadays researchers and engineers still resort to mining damage prediction methods proposed in the 1950s. Although such methods possess numerous advantages (like simplicity of assumptions and solutions, vast methodrelated experience gathered during more than six decades of using them, etc.), the simplifications used in them, failing to assume numerous crucial properties of rock mass structure, strata quality, water conditions, etc., to an appropriate degree, may often lead to calculation results very different from measurement results. This is particularly important in the case of areas with high intensity of exploitation. Building appropriate numerical models and carrying out calculations with the use of numerical methods (Finite Element Method, Finite Difference Method, etc.) seems to offer a solution to the problem by giving a possibility of assuming a wider variety of factors [2]-[8]. Selecting a proper model, however, poses serious difficulties. For instance, a description of an undisturbed rock mass is already extremely difficult due to its structure, stratification, properties of rock mass, connections between layers and complicated tectonics. Furthermore, the rock mass in the vicinity of mining exploitation becomes subject to additional disturbances changing its properties. Such changes are difficult to determine and describe precisely, even in spite of the application of advanced calculation techniques. The first linear elastic models, elastic ones with modeled discontinuities, fractured models, as well as elastic-plastic models, failed to provide appropriate results for surface subsidence in comparison with the measurements. The differences were particularly observable in further areas of influence range. This problem was solved by means of using a transversely isotropic model. The anisotropy of elastic parameters of the model caused large limitation of influence range in comparison with earlier models. The results of those calculations were published in [10], [11]. An analysis of the appropriateness of the numerical model assumed for calculations was carried out by means of comparing the subsidence and slope of subsidence trough obtained from surveying measurement with the results of numerical calculations. If a proper matching of results was obtained, it was assumed that a selected 
numerical model was correct and further analyses commenced. The present paper presents not only a comparison of the results of subsidence and slope but also a comparison of the horizontal surface displacement obtained from geodesic measurement with the results obtained from numerical calculations. The author was fully aware of some potential difficulties and limitations with obtaining satisfactory results of horizontal displacement comparison in a $2 \mathrm{D}$ numerical model, as the problem should have been treated as three dimensional. Hence, those limitations motivated attempts at building a variety of numerical models in order to obtain satisfactory calculation results.

\section{THE INFLUENCE OF MODELING VARIOUS BOUNDARY CONDITIONS ON THE RESULTS OF SURFACE DISPLACEMENT: THE CASE OF PROSPEL-HANIEL MINE}

The mine carried out exploitation of the walls nos. 698 and 697 in the seam O/N at an average depth of $960 \mathrm{~m}$. The width of individual mined-out longwall panels was approx. $270 \mathrm{~m}$, with its run close to $980 \mathrm{~m}$, whereas their thickness ranged between $3.6 \mathrm{~m}$ and $4.3 \mathrm{~m}$ (Fig. 1). The exploitation was executed in the area only slightly disturbed by earlier mining works [12]. Numerical calculations based on Finite Element Method (FEM) were carried out for a measurement line situated in the middle part of exploitation, parallel to the face advance.

a)

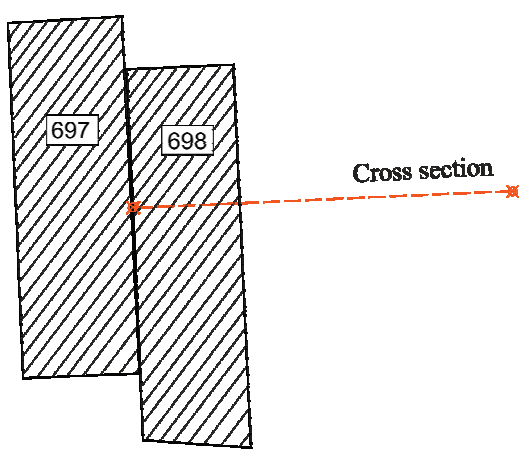

b)

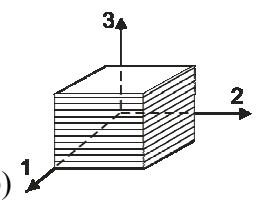

Fig. 1. Position of cross section in relation to exploitation (a) and presentation of transversally isotropic model used to describe the behaviour of the rock mass in the region of underground mining excavation (b)

The model consisted of a shield (2D model) modeled in a flat state of strain, built of approx. 40,000 elements with four nodes. According to the principles presented in detail in [11], the main rock strata of the analyzed area were modeled, as well as mininginduced weak zones. The physical and mechanical parameters of strata are presented in Table 1. For the rock mass in the area of exploitation, a transversely isotropic model was assumed, which is characterized by five parameters: $E_{1}=E_{2}, E_{3}, v=v_{21}=v_{12}, v_{31}$, and $G_{12}$. Assuming the plane of isotropy in the direction $1-2^{1}$, the shear modulus in the plane of isotropy $G_{12}$ can be calculated from the following formula

$$
G_{12}=\frac{E_{1}}{2\left(1+v_{12}\right)},
$$

whereas the parameter $G_{13}$ is determined from the formula presented by Lekhnitskii (assuming the lack of research results)

$$
G_{13}=\frac{E_{1} E_{3}}{E_{3}\left(1+2 v_{13}\right)+E_{1}} .
$$

Table 1. Modeled geological structure with the applied physical and mechanical parameters

\begin{tabular}{|c|c|c|c|c|}
\hline & & \multicolumn{3}{|c|}{$\begin{array}{r}\text { Physical and mechanical parameters } \\
\text { of rock layers }\end{array}$} \\
\cline { 3 - 5 } Layers & \multirow{2}{*}{$\begin{array}{c}\text { Thickness } \\
\text { of layers }[\mathrm{m}]\end{array}$} & $\begin{array}{c}\text { Unit weight } \\
\gamma[\mathrm{MPa} / \mathrm{m}]\end{array}$ & $\begin{array}{c}\text { Young's } \\
\text { modulus } \\
E_{2}[\mathrm{GPa}]\end{array}$ & $\begin{array}{c}\text { Poisson's } \\
\text { ratio } v\end{array}$ \\
\hline Tertiary & 60 & 0.018 & 1.40 & 0.33 \\
\hline Chalk & 300 & 0.021 & 2.00 & 0.25 \\
\hline Triassic & 180 & 0.023 & 2.20 & 0.20 \\
\hline Sandstone & 160 & 0.025 & 2.90 & 0.20 \\
\hline Shale & 140 & 0.023 & 2.20 & 0.20 \\
\hline Sandstone & 120 & 0.025 & 2.90 & 0.20 \\
\hline Carbon & 4 & 0.018 & 1.50 & 0.30 \\
\hline Shale & 336 & 0.023 & 2.20 & 0.20 \\
\hline
\end{tabular}

The numerical model selected for calculations is presented in Fig. 2; semi-infinite elements were used in the model. For the analyzed mining and geological situation, the relation of deformation moduli equal $E_{3} / E_{2}=8 \%$ was assumed.

\footnotetext{
${ }^{1}$ The observations of the strata disturbed by underground mining excavations reveal that the anisotropy properties of bedding rock mass are changing. These changes are the results of mining activities. Under the influence of new stress, arisen in the overburden rocks, the rock mass layers fracture, which subsequently affects diverse values of parameters, mostly in vertical and horizontal directions. The properties of the strata after the mining excavations reveal much larger discrepancies in values between the parameters in vertical direction and horizontal direction, compared only to its value in the embedded rock mass (not disturbed by underground mining exploitation).
} 
The calculation results of subsidence, slope and horizontal displacement are presented below and compared with the measurement results (Fig. 3). The comparison shows that assuming a transversely isotropic model was appropriate from the perspective of excellent matching of the curves of subsidence and slope, however the calculated horizontal displacements beyond the point of bending tend to be dramatically dif- ferent from the values obtained from surveying measurement (Fig. 3). Therefore, in order to achieve a better matching of horizontal displacement, it was decided to carry out further numerical calculations and changing the boundary conditions of the model.

Initially, the analysis embraced the influence of changes of two parameters of transversely isotropic model, i.e., Poisson's ratio $v$ (Fig. 4) and Kirchhoff

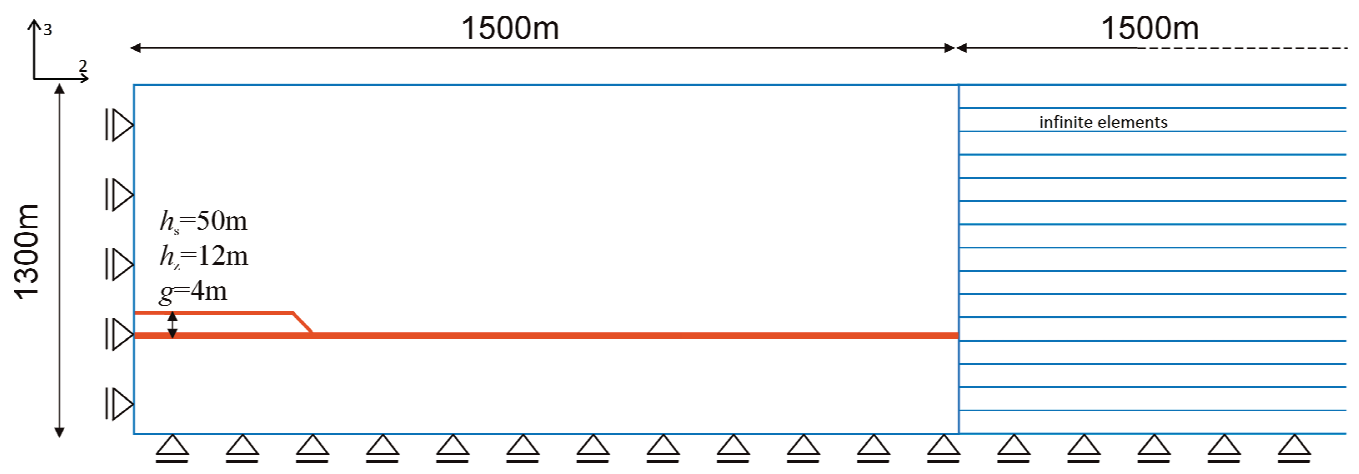

Fig. 2. Scheme of numerical model (with infinite elements) assumed for calculations
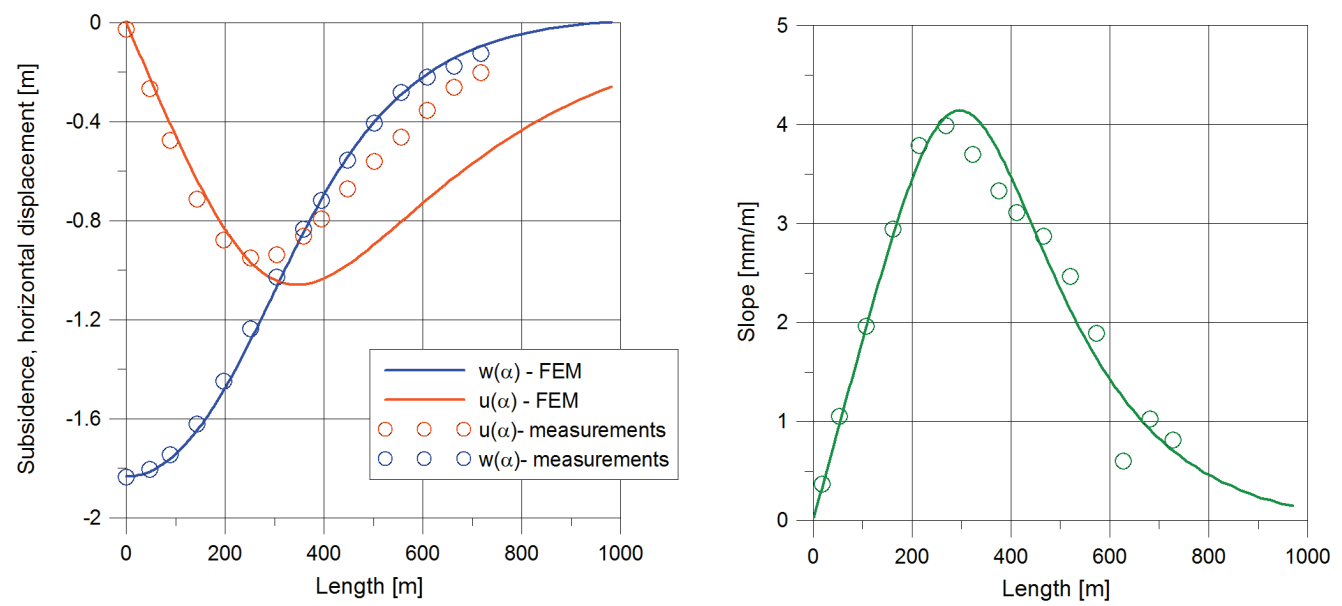

Fig. 3. Comparison of subsidence, horizontal displacement and slope for the trough calculated with the use of FEM with surveying measurement
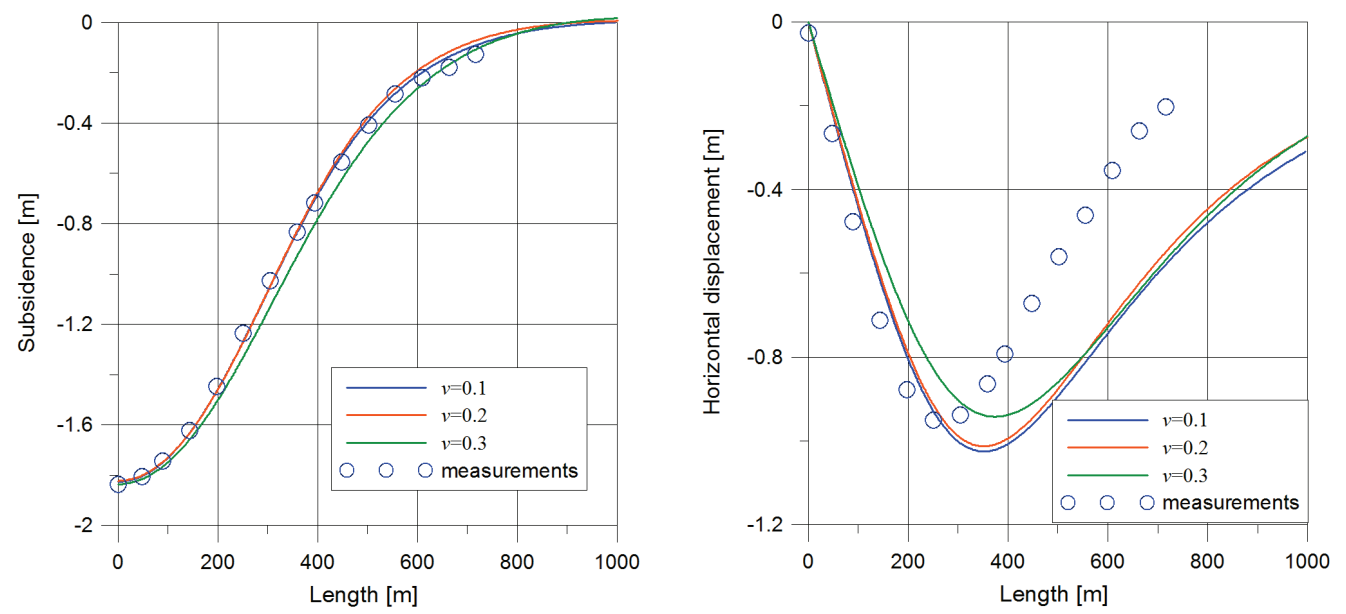

Fig. 4. Changes of values of subsidence and horizontal displacement for various values of Poisson's ratio 

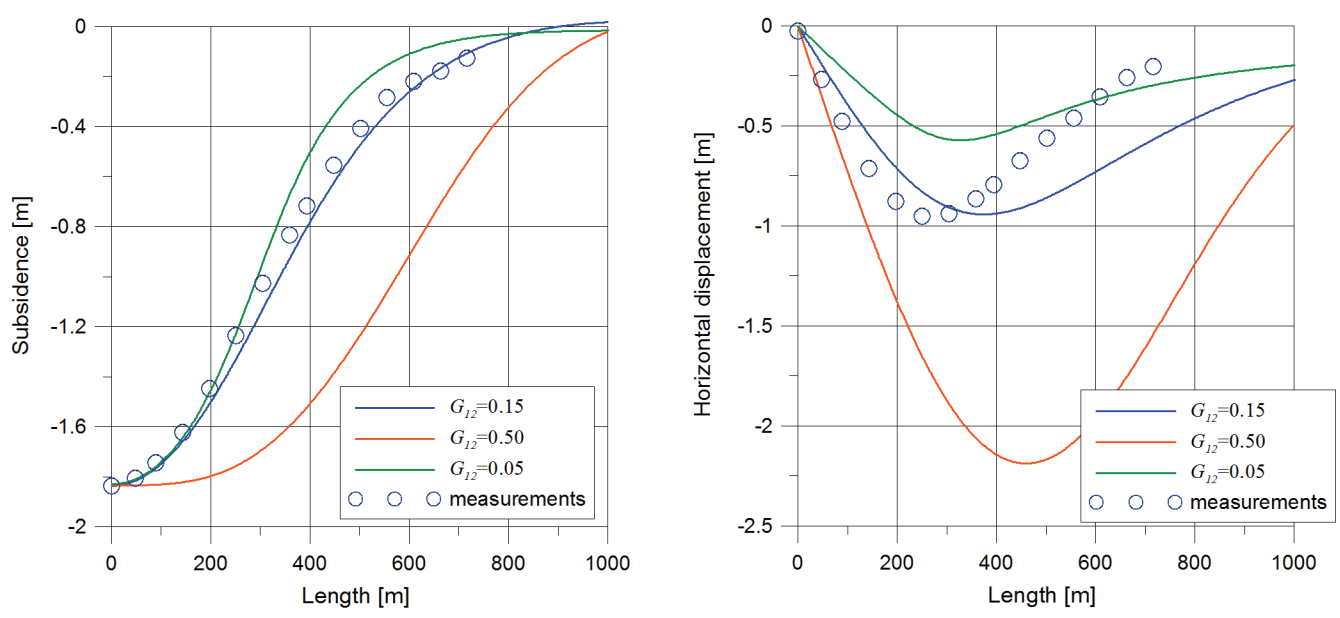

Fig. 5. Changes of values of subsidence and horizontal displacement for various values of Kirchhoff modulus $G_{12}$

modulus $G_{12}$ (Fig. 5), on the distribution of horizontal displacement.

It should be pointed out that the analyses of changes of values of elastic modulus and its relation $E_{3} / E_{2}$ were skipped, since the experience hitherto gathered during modeling mining-induced rock mass deformation clearly shows that both the value of elastic modulus for rock layers and the relation $E_{3} / E_{2}$ do not affect seriously the value of horizontal displacements. The value of elastic modulus, however, mainly affects surface subsidence, whereas $E_{3} / E_{2}$ is related to slope of subsidence trough. The value of $E_{2}$ is determined with the use of Hoek-Brown GSI criterion [1].

The calculations show that:

- the increase of Poisson's ratio $v$ causes the decrease of horizontal displacements, especially maximum displacements, but it does not affect their distribution,

- the change of value of Kirchhoff modulus $G_{12}$ seriously affects the shape of subsidence trough, however it does not affect the maximum value of subsidence. The maximum value of horizontal displacement largely depends on the value of Kirchhoff modulus $G_{12}$ but the influence of the value of Kirchhoff modulus $G_{12}$ on the shape of displacement is insignificant.

The analysis discussed above was carried out without assuming the changes of primary values of horizontal stress in the calculations. In order to determine to what extent the change of primary horizontal stress affects the results of displacement due to parallel changes of parameters $v$ and $G_{12}$, further numerical calculations were carried out. The following primary state of stress in bedded rock mass was assumed for the calculations

$$
p_{z}=\sum \gamma_{i} H_{i} \quad \text { and } \quad p_{x}=p_{z} \cdot \lambda
$$

For the calculations presented in Fig. 6 and Fig. 7, the value of lateral pressure coefficient was $\lambda=0.01$
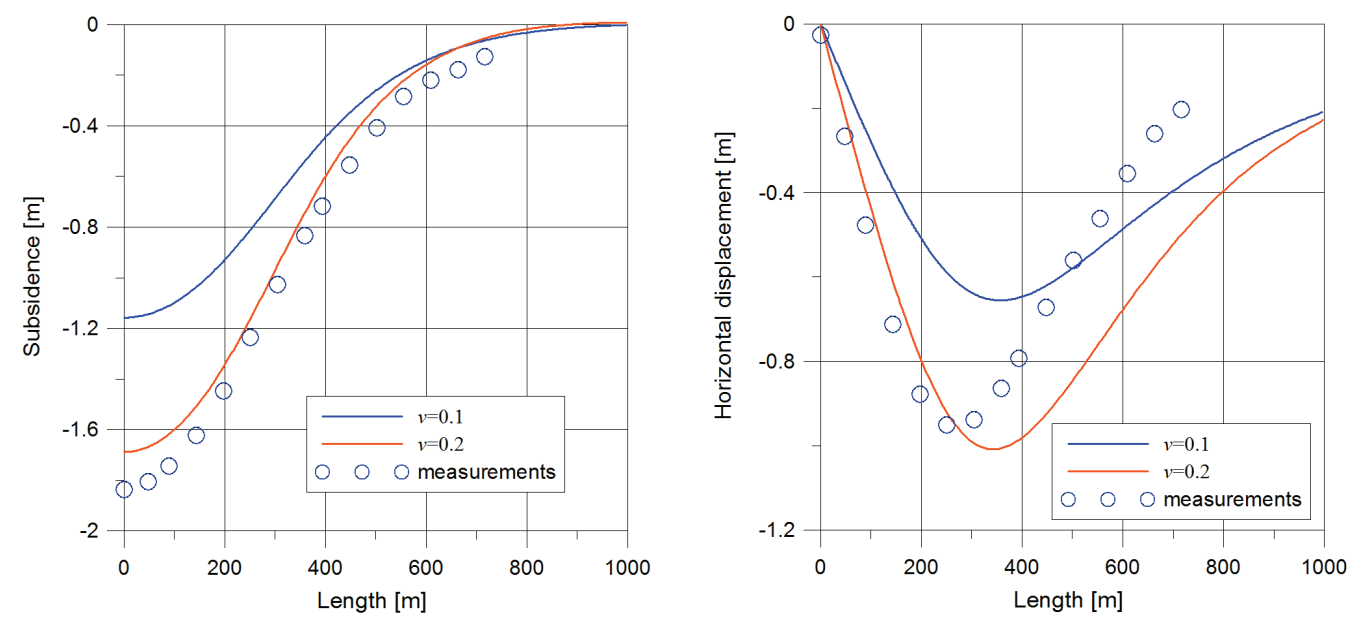

Fig. 6. Changes of values of subsidence and horizontal displacement for various values of Poisson's ratio and the value of lateral pressure coefficient $\lambda=0.01$ 

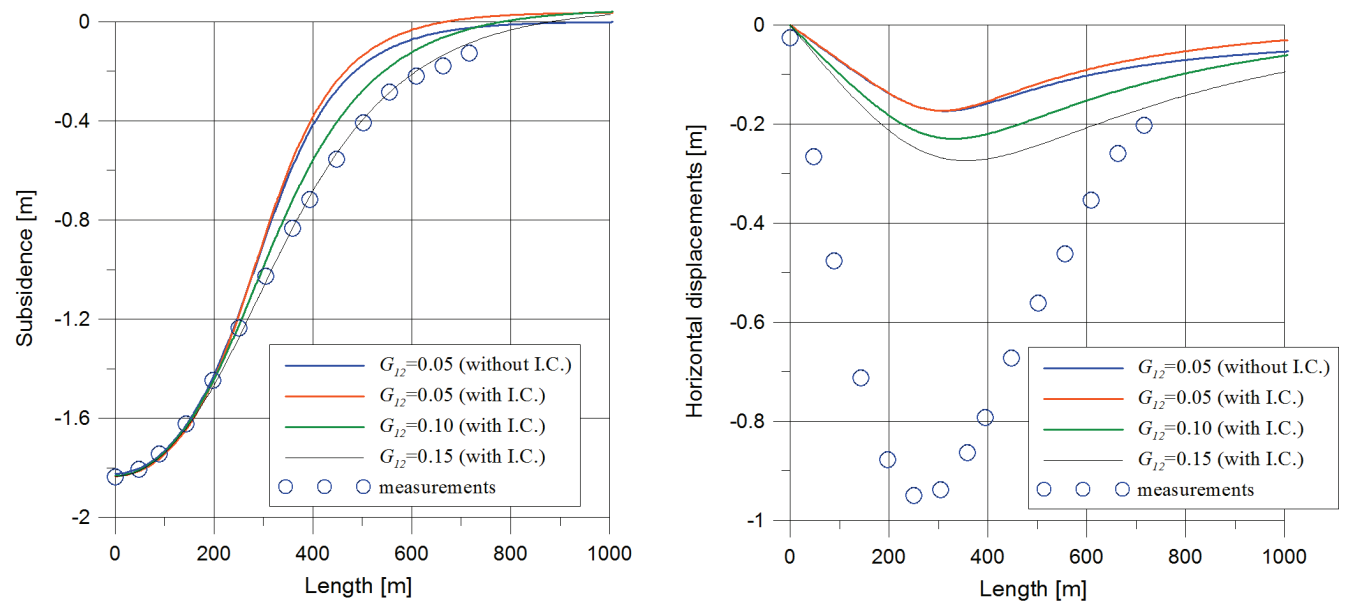

Fig. 7. Changes of values of subsidence and horizontal displacement for various values of Kirchhoff modulus $G_{12}$ and the value of lateral pressure coefficient $\lambda=0.01$ (I.C. means Initial Conditions)
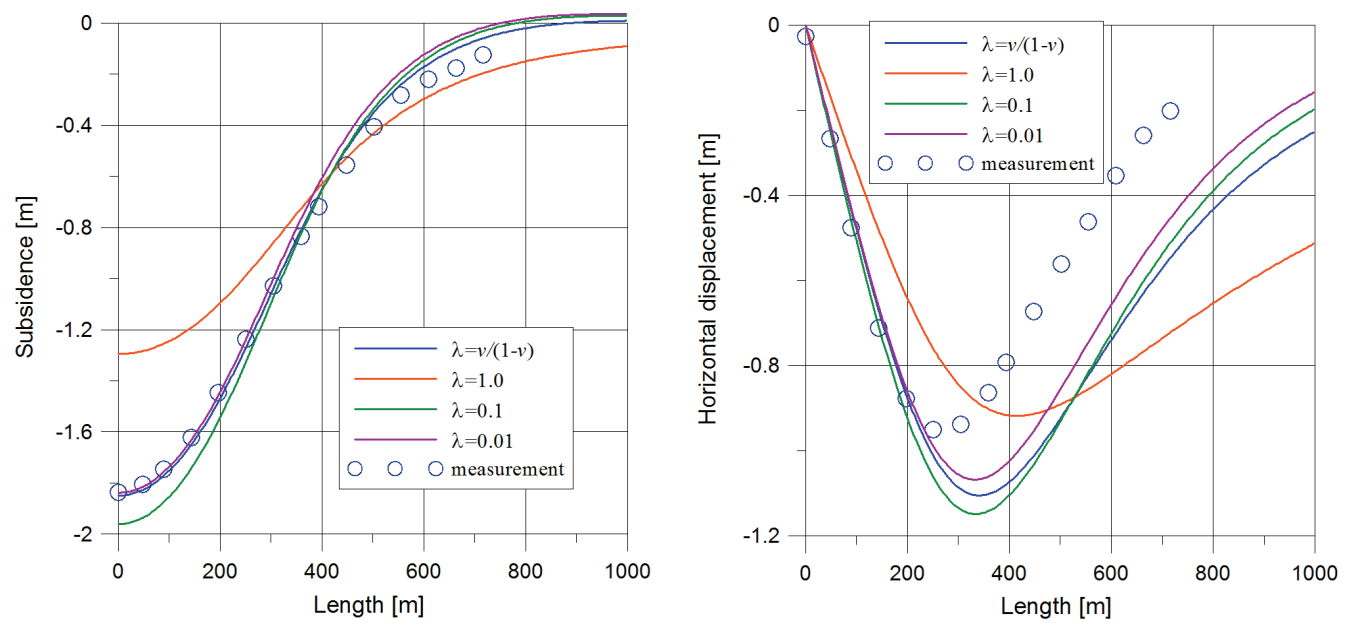

Fig. 8. Changes of values of subsidence and horizontal displacement for various values of lateral pressure coefficient $\lambda$
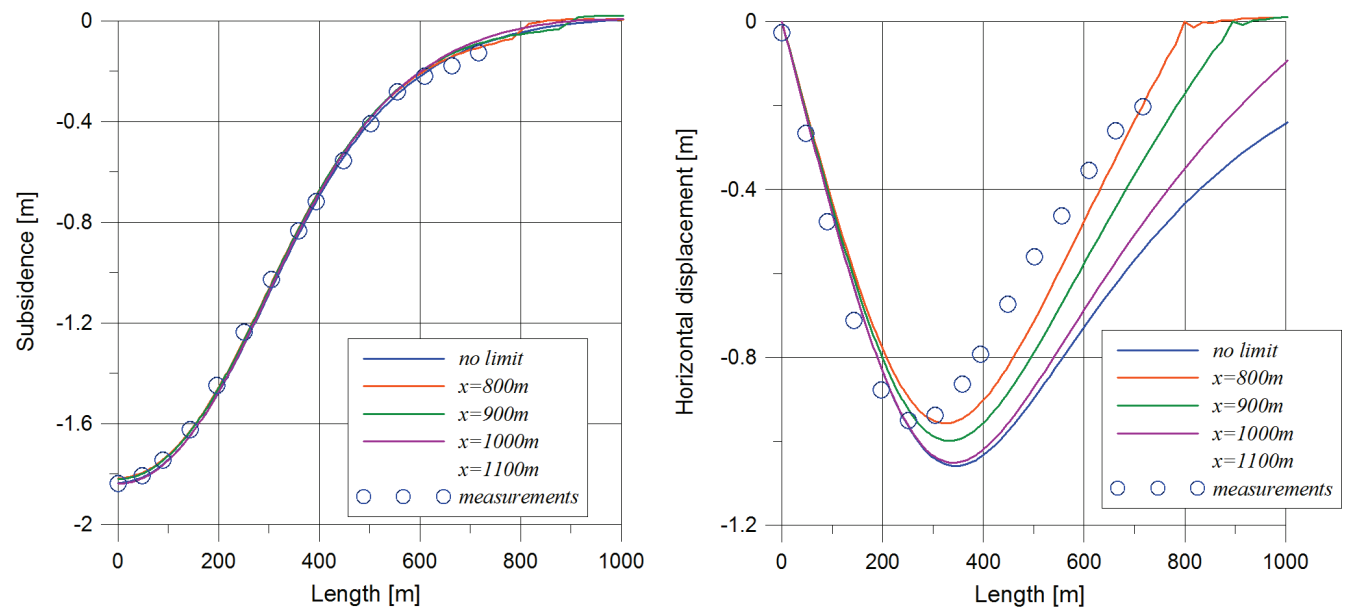

Fig. 9. Changes of values of subsidence and horizontal displacement for various lengths of the model

(,without I.C" means ,without Initial Conditions” where initial conditions are applied as initial state of stress).

The analysis showed that the assumption of the value of lateral pressure coefficient $\lambda=0.01$ and changing parameters $v$ and $G_{12}$ in a transversely isotropic model still failed to improve the character and the values of calculated horizontal displacements. Hence, further calculations occurred to be necessary 
for several higher values of lateral pressure equal $\lambda=0.1,0.25,1.0$, respectively (Fig. 8).

The calculations failed to provide the expected results, however the observations of modeling results showed that the application of semi-infinite elements might have been one of the reasons for moving the displacements in the direction of the right side of the model. Furthermore, the elements above the exploitation zone were $4 \mathrm{~m}$ long but their length increased to the value of above $35 \mathrm{~m}$ along with the distance to the zone. Hence, it was decided to carry out further calculations, resigning from the semi-infinite points for shields of varied lengths. Such calculations were made for the following distances: $800 \mathrm{~m}, 900 \mathrm{~m}$, $1,000 \mathrm{~m}$ and $1,100 \mathrm{~m}$. The calculation results are presented in Fig. 9.

Limiting the model size does not affect the value of subsidence seriously. Nonetheless, it affects the changes of values of horizontal displacement. Alongside with the decrease of model width to $800 \mathrm{~m}$, horizontal displacements practically have a similar course to the ones obtained from surveying measurement.

In order to verify to what extent vertical and horizontal displacements were affected by assuming an elastic-plastic model for the Tertiary layer, the calculations were executed, in which an elasticplastic model with Mohr-Coulomb strength criterion was assumed for the Tertiary layer. The analysis indicated the influence of changes of values of

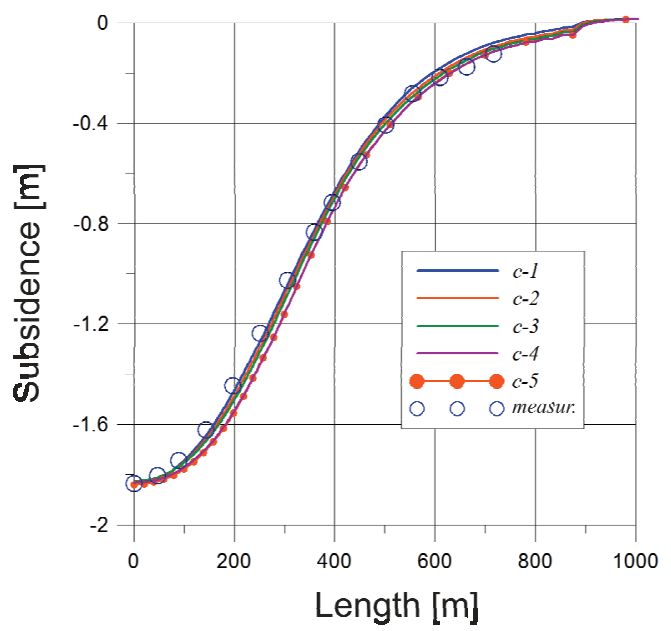

(Tables 2 and 3). The obtained results are presented in Figs. 10 and 11.

Table 2. Strength parameters assumed for the Tertiary layer

\begin{tabular}{|c|c|c|}
\hline $\begin{array}{c}\text { Calculation } \\
\text { variant }\end{array}$ & $\varphi\left[^{\circ}\right]$ & $c[\mathrm{MPa}]$ \\
\hline $\mathrm{c}-1$ & \multirow{5}{*}{22} & 0.440 \\
\hline $\mathrm{c}-2$ & & 0.220 \\
\hline$c-3$ & & 0.110 \\
\hline $\mathrm{c}-4$ & & 0.010 \\
\hline$c-5$ & & 0.001 \\
\hline
\end{tabular}

Table 3. Strength parameters assumed for the Tertiary layer

\begin{tabular}{|c|c|c|}
\hline $\begin{array}{c}\text { Calculation } \\
\text { variant }\end{array}$ & $\varphi\left[^{\circ}\right]$ & $c[\mathrm{MPa}]$ \\
\hline$\varphi-1$ & \multirow{4}{*}{11} & 0.220 \\
\hline$\varphi-2$ & & 0.100 \\
\hline$\varphi-3$ & & 0.010 \\
\hline$\varphi-4$ & & 0.001 \\
\hline
\end{tabular}

The calculations show that assuming an elasticplastic model with Mohr-Coulomb strength criterion for the Tertiary layer, as well as using the process of exploitation simulation ${ }^{2}$, allows us to obtain the values of subsidence similar to the results of measurements and approach the results of horizontal displacement obtained from surveying measurement for appropriately selected strength parameters. It was also ob-

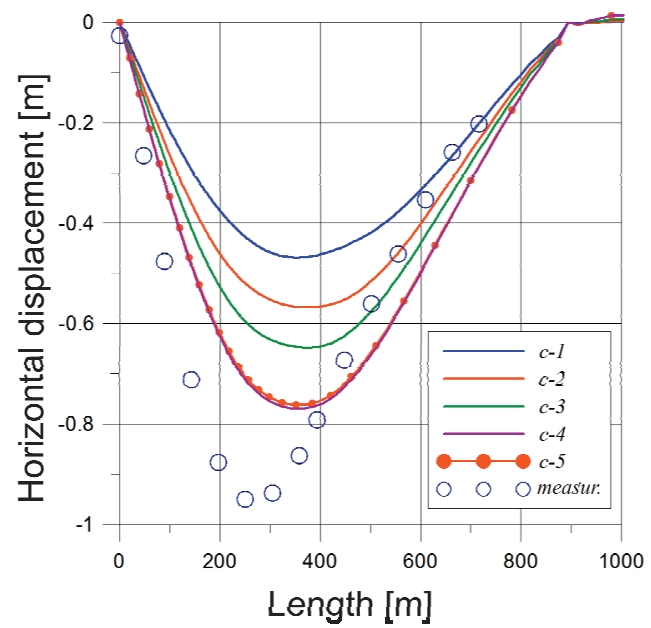

Fig. 10. Changes of values of subsidence and horizontal displacement for various values of strength parameters assumed for the Tertiary layer

internal friction angle $\varphi$ and cohesion $c$ on the distribution of horizontal displacement. The calculations were carried out for the model with a width of $800 \mathrm{~m}$ and determined values of strength parameters
${ }^{2}$ In all the models a simulation of exploitation advancement was carried out by means of eliminating elements attributed to the layer of coal in consecutive calculation steps. 

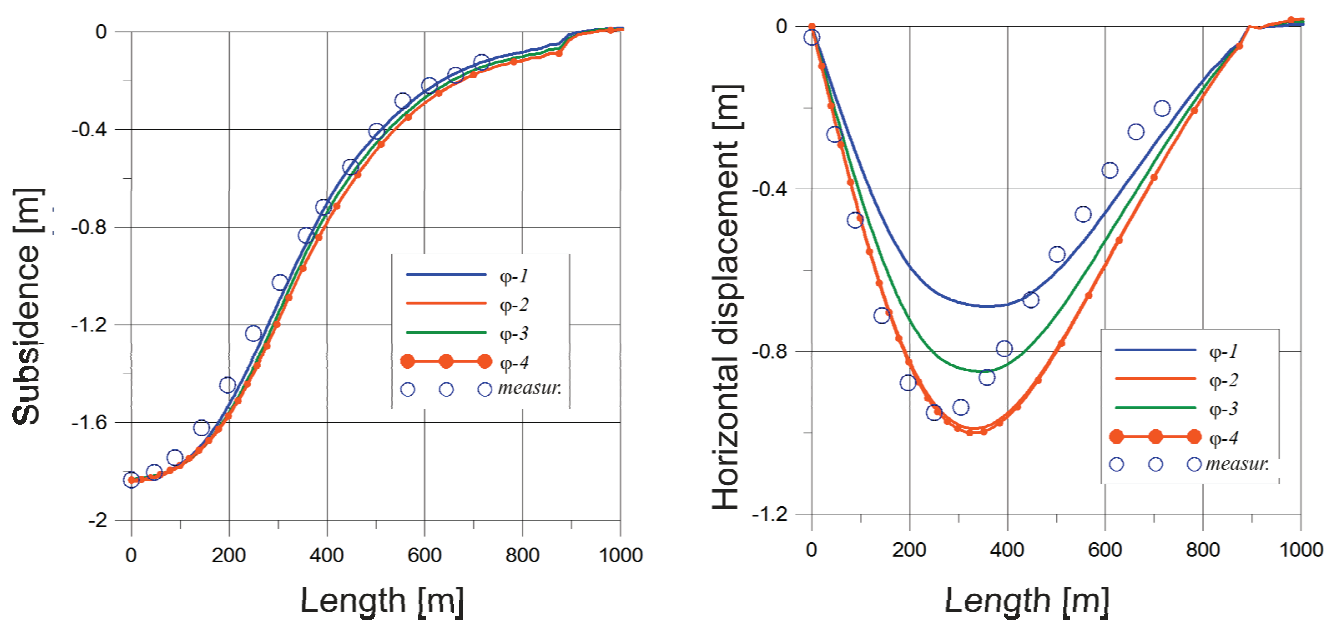

Fig. 11. Changes of values of subsidence and horizontal displacement for various values of strength parameters assumed for the Tertiary layer

served that the value of cohesion of the modeled layer seriously affected the distribution of horizontal displacement, i.e., along with the decrease of that value, horizontal displacements increased. Also the decrease of internal friction angle caused the increase of value of calculated horizontal displacements. However, in spite of the fact that the calculations were carried out for numerous variants (various $c$ and $\varphi$ ), it occurred to be impossible to obtain better matching results than the ones for the models presented in Fig. 9.

\section{3D CALCULATIONS OF SURFACE DEFORMATION FOR "SIERSZA" MINE}

"Siersza" Coal Mine carried out exploitation in the seam 209/210 with the walls 501 and 502 at the depth of 325-330 m. A total width of longwall panels was $350 \mathrm{~m}$ and their panels run was approx. 1000-1080 m [9], [11]. It was also assumed that an average thickness of exploitation was $g=3.0$. The rock mass in the area of the mine consisted of Trias- sic rocks deposited at the depth of approx. $80 \mathrm{~m}$. It was mainly sandstone packages with an average thickness of approx. $64 \mathrm{~m}$ and dolomites with an average thickness of approx. $10 \mathrm{~m}$. Below, there were "laziskie" layers in the form of sandstones, shale and carbon, where exploitation took place. A numerical analysis was carried out for the abovementioned walls 501 and 502, which embraced numerical model construction based on FEM, determining its geometry and layered structure, then a selection of deformation parameters of modeled rock strata, and, finally, carrying out the calculations. The analyzed 3D model with the dimensions of $1950 \times 2770 \times 430 \mathrm{~m}$ was made of 332,687 elements with eight nodes, modeled as an elastic transversely isotropic material (Fig. 12).

Two weak zones were distinguished in the model above the exploited seam, with the heights of: $h_{z w}=6 \mathrm{~m}-$ high caving zone, $h_{s}=34 \mathrm{~m}-$ fracture zone (it was assumed that the fracture zone would reach the layer of sandstone with the thickness of $40 \mathrm{~m}$, which will not be subject to fracture due to its high strength parameters and considerable thickness).

Table 4. Parameters of transversely isotropic model for the seam 209/210 of "Siersza" Coal Mine

\begin{tabular}{|c|c|c|c|c|c|}
\hline $\begin{array}{l}\text { Strata constructing } \\
\text { rock mass }\end{array}$ & $\begin{array}{c}E_{3} \\
{[\mathrm{GPa}]}\end{array}$ & $\begin{array}{c}E_{1}=E_{2} \\
{[\mathrm{GPa}]}\end{array}$ & $v_{12}=v_{31}$ & $\begin{array}{c}G_{12} \\
{[\mathrm{GPa}]}\end{array}$ & $\begin{array}{c}G_{13} \\
{[\mathrm{GPa}]}\end{array}$ \\
\hline Overburden & 0.120 & 0.80 & \multirow{5}{*}{0.2} & 0.033 & 0.099 \\
\hline Floor & 0.120 & 0.80 & & 0.033 & 0.099 \\
\hline Carbon & 0.105 & 0.70 & & 0.029 & 0.087 \\
\hline *Fracture zone & \multicolumn{2}{|c|}{0.59} & & \multicolumn{2}{|c|}{0.24} \\
\hline *Caving zone & \multicolumn{2}{|c|}{0.059} & & \multicolumn{2}{|c|}{0.024} \\
\hline
\end{tabular}

* For Quaternary layer, fracture zone and caving zone, an elastic model with equivalent deformation parameters was assumed. 
The initial values of elastic moduli for those strata were selected with the use of GSI classification. By means of using laboratory data of compres-

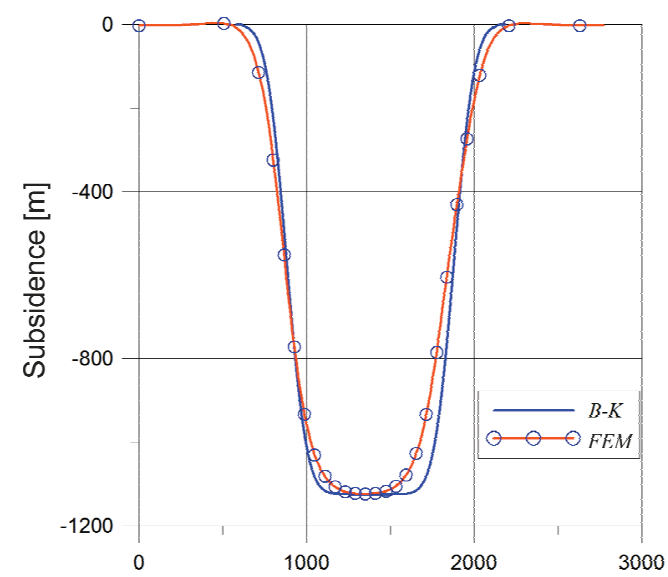

a)

Length [m] sive strength of particular rock layers creating the overburden and after determining the value of GSI, the value of parameter $E_{2}$ was obtained (Table 4 ).

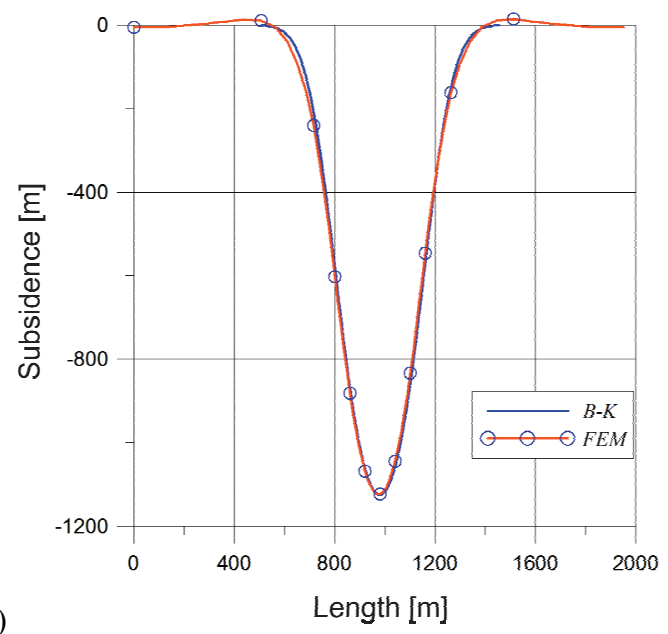

Fig. 12. Changes of values of subsidence for a line parallel to the longwall panel (a) and for a line perpendicular to the longwall panel (b)
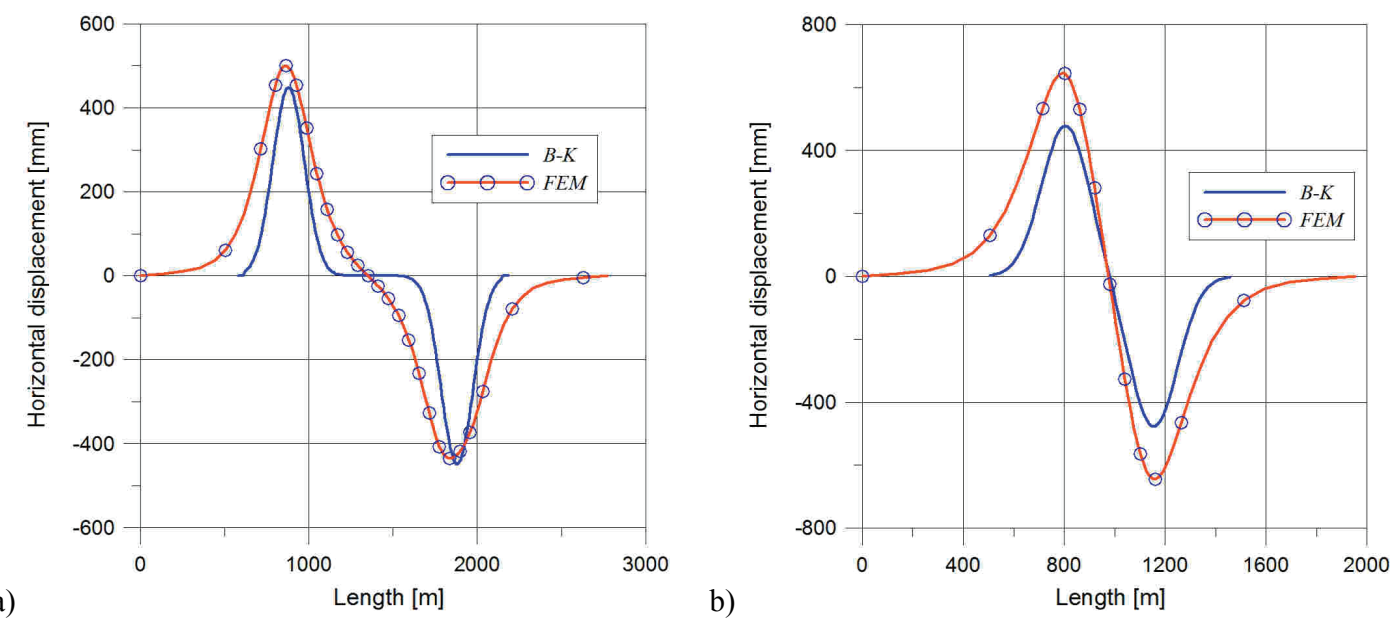

Fig. 13. Changes of values of horizontal displacement for a line parallel to the longwall panel (a) and for a line perpendicular to the longwall panel (b)
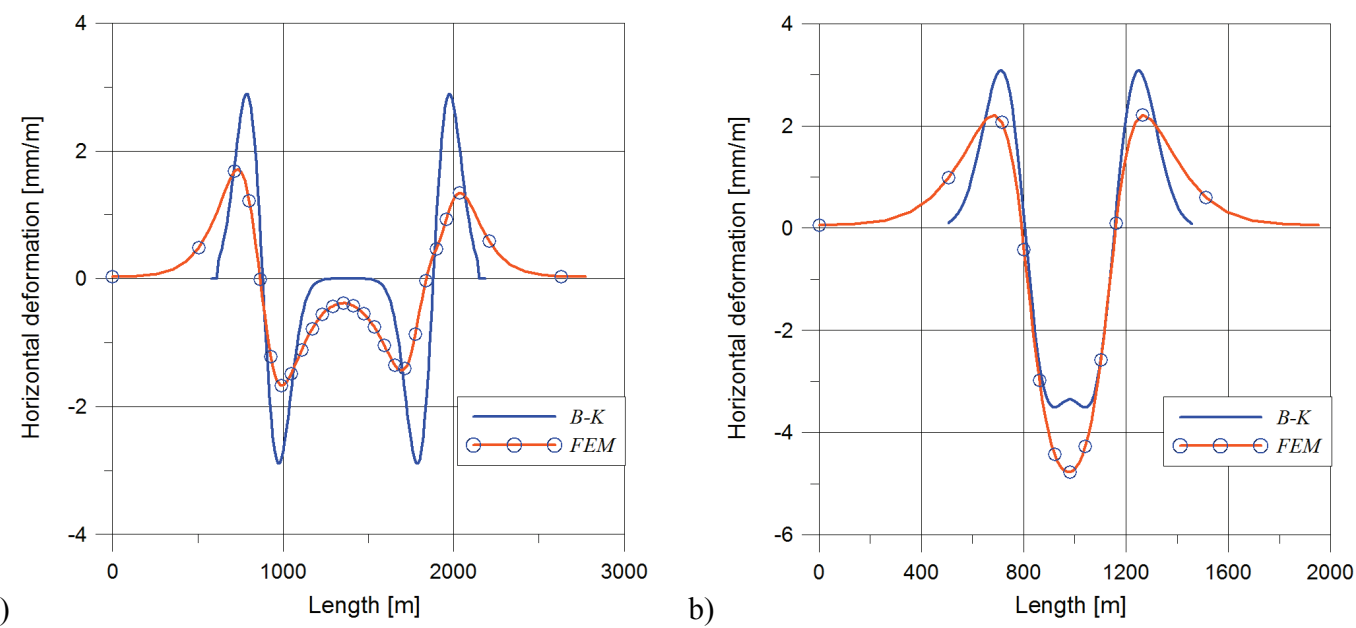

Fig. 14. Changes of values of horizontal deformation for a line parallel to the longwall panel (a) and for a line perpendicular to the longwall panel (b) 
A particular anisotropy value of the modeled medium was $15 \%$, hence the modulus of elasticity $E_{3}$ was: $E_{3}=0.15 E_{2}$.

An accurate matching of results of numerical model calculations was presented by means of comparing them with the results of calculations based on Knothe theory (due to the lack of measurements of horizontal displacements). The comparison was made for a perpendicular line and a parallel line to the longwall panel, which crossed in the middle of the modeled exploitation.

The results indicate that a better matching of both subsidence and slope was obtained for the line perpendicular to the longwall panel. Change of slope was only $\Delta T=2 \%$ both in the zone of tension and the zone of compression, whereas the modeled horizontal displacements indicated the similarity of character of the line's course but the maximum values obtained from FEM calculations were approx. 25\% larger than the values calculated with the use of Budryk-Knothe theory (with the assumption that $B=0.40 r$ ). Similarly, numerically calculated horizontal deformations indicated the values $26 \%$ higher than the ones calculated with the use of Budryk-Knothe method. Larger differences were obtained in the line parallel to the longwall panel. The difference in the values of maximum slope was $\Delta T=12 \%$ in the zone of tension, and $\Delta T=6 \%$ in the zone of compression.

The maximum horizontal displacement calculated with the use of FEM were different by $11 \%$, whereas the minimum - by $4 \%$, in relation to the ones calculated with the use of Budryk-Knothe method. Larger differences appeared while determining compressive and tensile horizontal deformations.

\section{CONCLUSIONS}

Since the advanced numerical methods are still a relatively new solution in determining rock mass deformation, the researchers are still gaining experience in applying such methods. The analysis presented above prove that modelling of the strata in the region of underground mining influence can correctly describe the surface vertical deformations but the horizontal deformations (displacements and strain) needs some additional assumptions (like size of the model). Right now it is very hard to use numerical method to correctly predict the surface deformations using numerical modelling because too many factors have an impact on the result obtained. The modelling of the surface deformations needs time and some improvements to be successfully applied in determining mining-induced deformations of surface and within the rock mass. The game is worth a candle because the obtained results of numerical modelling of mining induced surface deformation may include huge number mining, geological and technical factors.

\section{ACKNOWLEDGMENT}

The project was financed from the means of National Science Center granted on the grounds of decision No. DEC2011/01/D/ST8/07280.

\section{REFERENCES}

[1] Hoek E., Brown E.T., Practical Estimates of Rock Mass Strength, Int. J. Rock Mech. Min Sci. and Geomech., 1997, 34, 8, 1165-1186.

[2] Keilich W., Seedman R., Aziz N., Numerical Modelling of Mining Induced Subsidence, Coal Operations' Conference, July 6-7 2006, 313-326.

[3] NAJJAR Y., ZAMAN M., Numerical modeling of ground subsidence due to mining, Int. J. of Rock Mech. Sci. \& Geomech., 1993, 30(7), 1445-1448.

[4] Salamon M.D.G., Chugh Y.P., Yang G., A numerical approach to subsidence prediction and stress analysis in coal mining using a laminated model, Int. J. of Rock Mech. Sci. \& Geomech., 1993, 30(7), 1419-1422.

[5] SHIPPMAN G.K., Numerical investigation of elastic behaviour around longwall excavations, $\mathrm{PhD}$ Dissertation, University of Nottingham, 1970.

[6] SiRIWARDANE H.J., A numerical procedure for prediction of subsidence caused by longwall mining, 5th Int. Conf. on Numerical Methods in Geomechanics, Nagoya 1985.

[7] SzostaK-ChrZANowsKa A., Wplyw podziemnej eksploatacji złóż o skomplikowanej geometrii na powierzchni terenu $w$ świetle badań Metody Elementów Skończonych, Praca Doktorska, Kraków 1988.

[8] Chrzanowski A., Szostak-Chrzanowski A., Bastin G., LUTES J., Monitoring and modelling of ground subsidence in mining areas: case studies, Geomatica, 2000, 54(4), 405-413, Canadian Institute of Geomatics.

[9] Tajduś K., SRoKa A., TAJduś A., Preusse A., Three dimensional modeling of surface displacements as a result of underground longwall panel extraction, 29th Ground Control in Mining, ISBN 978-0-9789383-3-8, pp. 105-110, Morgantown, USA, 2010.

[10] TAJDUŚ K., Determination of the value of the strain parameters for strata rock mass in the region of underground mining influence, Dissertation ISBN 978-3-86797-061-7, VGE Verlag GmbH, Essen, 2009, No. 2.

[11] TAJDUŚ K., Numerical simulation of underground mining exploitation influence upon terrain surface, Archives of Mining Sciences, ISSN 0860-7001, 2013a, Vol. 58, No. 3, 605-616 (IF. 0.319).

[12] TAJDUŚ K., Mining-inducted surface horizontal displacement: The case of BW Prosper Haniel mine, Archives of Mining Sciences, ISSN 0860-7001, 2013b, Vol. 58, No. 4, 1037-1055 (IF. 0.319). 